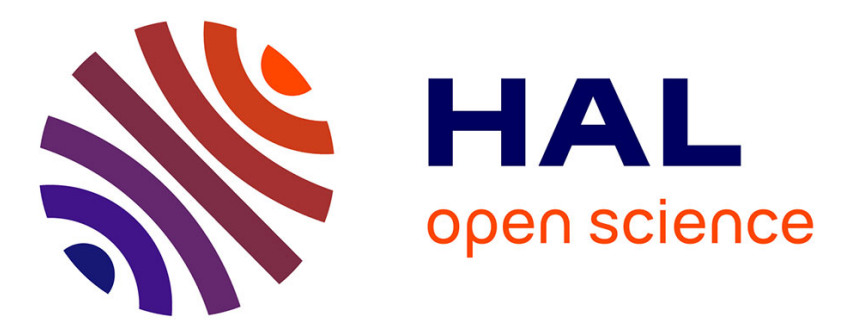

\title{
Shear viscosity measurements of nitrobenzene-n-hexane critical mixture
}

D. Beysens, S.H. Chen, J.P. Chabrat, L. Letamendia, J. Rouch, C. Vaucamps

\section{To cite this version:}

D. Beysens, S.H. Chen, J.P. Chabrat, L. Letamendia, J. Rouch, et al.. Shear viscosity measurements of nitrobenzene-n-hexane critical mixture. Journal de Physique Lettres, 1977, 38 (10), pp.203-206. 10.1051/jphyslet:019770038010020300 . jpa-00231360

\section{HAL Id: jpa-00231360 https://hal.science/jpa-00231360}

Submitted on 1 Jan 1977

HAL is a multi-disciplinary open access archive for the deposit and dissemination of scientific research documents, whether they are published or not. The documents may come from teaching and research institutions in France or abroad, or from public or private research centers.
L'archive ouverte pluridisciplinaire HAL, est destinée au dépôt et à la diffusion de documents scientifiques de niveau recherche, publiés ou non, émanant des établissements d'enseignement et de recherche français ou étrangers, des laboratoires publics ou privés. 


\title{
SHEAR VISCOSITY MEASUREMENTS OF NITROBENZENE-n-HEXANE CRITICAL MIXTURE
}

\author{
D. BEYSENS
}

Service de Physique du Solide et de Résonance Magnétique, Centre d'Etude Nucléaire de Saclay, BP n 2, 91190 Gif sur Yvette, France

\section{S. H. CHEN}

Nuclear Engineering Dept. Massachusetts Institute of Technology, Cambridge, Massachusetts 02139, U.S.A.

\section{J. P. CHABRAT, L. LETAMENDIA, J. ROUCH and C. VAUCAMPS \\ Laboratoire d'Optique Moléculaire, E.R. $n^{\circ} 134$ du C.N.R.S., Université de Bordeaux I, 33405 Talence, France}

(Reçu le 24 mars 1977, accepté le 19 avril 1977)

\begin{abstract}
Résumé. - On a mesuré la viscosité de cisaillement du mélange critique nitrobenzène-n-hexane dans un large domaine de température $\left(0,003^{\circ} \mathrm{C}<T-T_{\mathrm{c}}<45^{\circ} \mathrm{C}\right)$. A partir d'une analyse statistique des résultats, on montre que la viscosité s'écrit comme le produit d'un terme régulier par un terme faiblement divergent (exposant critique $Y=0,043$ ). Ce résultat est en accord avec la théorie des groupes de renormalisation.
\end{abstract}

\begin{abstract}
The shear viscosity of the critical mixture nitrobenzene-n-hexane has been measured in a large temperature domain $\left(0.003{ }^{\circ} \mathrm{C}<T-T_{\mathrm{c}}<45^{\circ} \mathrm{C}\right)$. From a statistical analysis of the data it is shown that the viscosity can be written as a product of a regular term and a weak power law divergence (critical exponent $Y=0.043$ ). This result agrees well with renormalization-group predictions.
\end{abstract}

1. Introduction. - Anomalous increase of the shear viscosity $\eta$ has been experimentally observed in many binary liquid systems near their critical consolute point [1]. However, in most of the experimental works, the measurements were restricted to the critical region $\left(T-T_{\mathrm{c}}<10^{\circ} \mathrm{C}\right)$ and therefore no definite conclusion could be drawn for the most probable form of both regular and non-regular parts of $\eta$.

In this letter, we report measurements of the shear viscosity of the critical binary mixture nitrobenzenen-hexane $\left({ }^{1}\right)$, from $T-T_{\mathrm{c}} \simeq 3 \times 10^{-3}{ }^{\circ} \mathrm{C}$ up to $T-T_{\mathrm{c}} \simeq 45^{\circ} \mathrm{C}$. A statistical analysis of the data allows us to propose the following analytical form for the viscosity :

$$
\eta=\eta_{0} \cdot \exp \left(\frac{E}{1+\varepsilon}\right) \cdot \varepsilon^{-Y}
$$

( $\left.{ }^{1}\right)$ Viscosity of nitrobenzene-hexanes $\left(T_{\mathrm{c}} \simeq 14^{\circ} \mathrm{C}\right)$ has already been measured by Drapier [2], Semenchenko and Zorina [3] and Szafronska [4], but the critical concentration was not used and the accuracy of measurements was poor near $T_{\mathrm{c}}$. where $\eta_{0}=(143 \pm 5) 10^{-6} \mathrm{P}$ and $E=3.58 \pm 0.04$ are constants, $\varepsilon=\left(T-T_{\mathrm{c}}\right) / T_{\mathrm{c}}$ and $Y$ is a critical exponent found to be equal to $0.0430 \pm 3 \times 10^{-4}$.

2. Experimental. - The kinetic viscosity $\eta / \rho$ ( $\rho$ density) was measured with a Cannon-Tilting viscosimeter identical to that widely used by Allen's group [5]. The viscosimeter was filled with spectroscopic grade nitrobenzene and $n$-hexane at the critical concentration ( 0.51 weight fraction of nitrobenzene according to ref. [6] ; experimental : $0.509 \pm 0.007$ ). In order to prevent any external contamination, the sample was frozen in liquid nitrogen and the viscosimeter sealed under vacuum. The sealed viscosimeter was fixed on a rotary mount and placed in a very large volume (300 1) water bath which was thermally stabilized, giving a constant temperature within $\pm 2 \times 10^{-3}{ }^{\circ} \mathrm{C}$ over a period greater than $1 / 2$ hour. During this time interval, about 10 measurements of the flow time can be performed. A greater accuracy on the thermal stability is not needed near $T_{\mathrm{c}}$ because, as we shall discuss later, due to the shear stress induced by the flow in the capillary, values of the viscosity at $T-T_{0} \lesssim 10^{-2}{ }^{\circ} \mathrm{C}$ are not reliable. The flow time 
of the required volume of liquid between two reference marks was recorded with a chronometer, both accuracy and reproductibility being $\simeq \pm 0.3 \%$. The temperature of the bath was measured with a high precision calibrated mercury thermometer $\left( \pm 2 \times 10^{-3} \mathrm{o}\right)$.

A laser source was used to determine the critical consolute temperature $T_{\mathrm{c}}=(20.000 \pm 0.002){ }^{\circ} \mathrm{C}$ : both the maximum of turbidity $\left({ }^{2}\right)$ and the appearance, close to $T_{c}$, of the images $\left({ }^{3}\right)$ were observed. Moreover the meniscus was seen to appear in about the middle of the sample, which is a very good test of the criticity of the mixture.

Since we measure the kinetic viscosity, the density $\rho$ has to be known in order to deduce the shear viscosity. Measurements of Piekara [8] were used and extrapolated to the actual concentration.

INFLUENCE OF THE SHEAR RATE. - It is well known that the experimental value of the shear viscosity near a critical point strongly depends upon the method used to perform measurements. A critical analysis of these phenomena has been done by G. Carini et al. [9] and D. W. Oxtoby [10].

In our experiment, it is well understood that when the characteristic time associated with the velocity gradient becomes of the same order as the decay time of the concentration fluctuations, the experimental values of the viscosity can be affected. The shear rate (i.e. the transverse gradient of velocity : $-\mathrm{d} v / \mathrm{d} r$ in a cylindrical tube) has to be compared to the inverse correlation time $1 / \tau$ of the concentration fluctuations. These quantities are respectively equal to :

$$
\begin{aligned}
& -\frac{\mathrm{d} v}{\mathrm{~d} r}=\frac{\rho g R}{8 \eta} \\
& \frac{1}{\tau}=\frac{k_{\mathrm{B}} T}{6 \pi \eta \zeta^{3}} .
\end{aligned}
$$

We have assumed a Poiseuille flow. $\rho, g$ and $R$ are respectively the density of the fluid, the gravity constant and the capillary tube radius.

In the critical region, the correlation time $\tau$ is physically identified with the decay time of a brownian droplet of extent $\zeta, k_{\mathrm{B}}$ is the Boltzmann constant.

The flow method is not reliable, unless $\tau$ is shorter than $(-\mathrm{d} v / \mathrm{d} r)^{-1}$. For given experimental conditions, the comparison of eq. (2) and (3) leads to a condition on the correlation length $\zeta$, or equivalently to $\varepsilon=\left(T-T_{\mathrm{c}}\right) / T_{\mathrm{c}}$. In our case $\left(R=10^{-2} \mathrm{~cm}\right.$, $\left.\rho \simeq 1 \mathrm{~g} / \mathrm{cm}^{3}, g \simeq 10^{3} \mathrm{~cm} \cdot \mathrm{s}^{-2}\right)$, we obtain $\zeta<10^{3} \AA$. With the following law for the correlation length [11]

$$
\zeta=2.3(\varepsilon)^{-0.63}(\AA),
$$

$\left(^{2}\right)$ Turbidity is the rate of loss of light intensity from its own scattering [7].

$\left({ }^{3}\right)$ The images correspond to small angle light-scattering from very slow concentration fluctuations. we get

$$
T-T_{\mathrm{c}} \gtrsim 0.01^{\circ} \mathrm{C} \text { or } \varepsilon \gtrsim 3 \times 10^{-5} .
$$

3. Experimental results and discussion. - On figure 1 are plotted the variations of the shear viscosity versus $T-T_{\mathrm{c}}$. The usual increase of $\eta$ near $T_{\mathrm{c}}$ is observed and, as expected from the influence on the shear rate, viscosity saturates for $T-T_{\mathrm{c}} \lesssim 10^{-2}{ }^{\circ} \mathrm{C}$. Therefore, only data obtained for $T-T_{\mathrm{c}}>10^{-2}{ }^{\circ} \mathrm{C}$ will be taken into account in what follows.

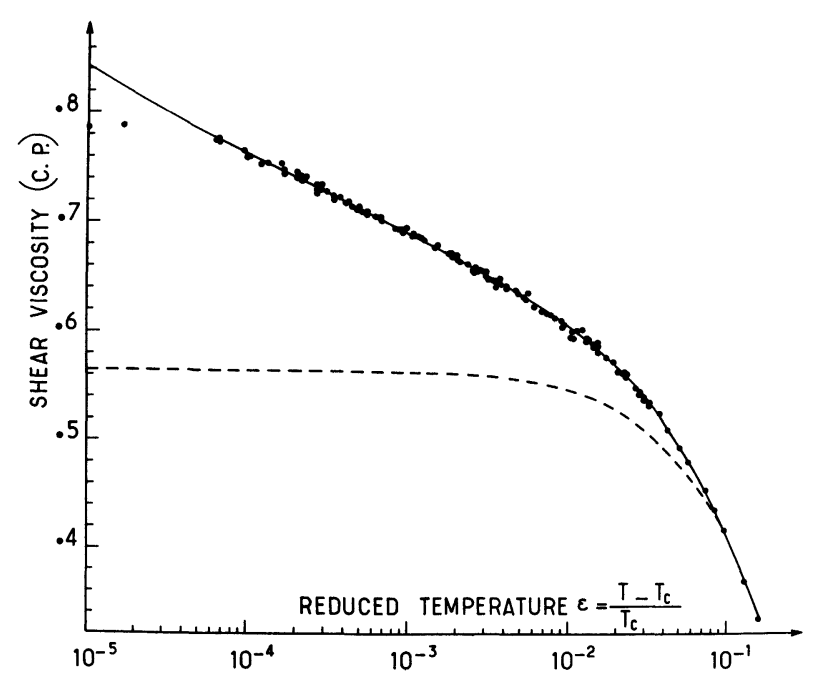

FIG. 1. - Viscosity against reduced temperature (Linear-Log scale). The solid line is the best fit of the data to eq. (a-1). The dashed line is an Arrhenius plot with $E=3.58$ and $\eta_{1}=157.3$.

The very involved problem of the critical behaviour of transport coefficients has been widely studied. From a mode-mode coupling approach, Kawasaki and Lo [12] divide the viscosity into a regular part $\eta_{\text {reg }}$ and a singular one $\Delta \eta$. The singular part $\Delta \eta$ is further expressed in terms of an integral which is well-behaved when $T \rightarrow T_{\mathrm{c}}$ [13]. On the other hand, from experimental findings, weak singularities have been proposed for $\Delta \eta$ : power law, cusp or logarithmic divergence [5]. In their careful study of the critical behaviour of the viscosity of 2-6 lutidine-water mixture, Gulari et al. [14] have shown that the singular part $\Delta \eta$ is very sensitive to the analytical form used to describe $\eta_{\text {reg }}$. Very recently, from a critical reexamination of the existing viscosity data, Calmettes [15] arrives at the following most probable analytical form for the viscosity":

$$
\eta=\eta_{\mathrm{reg}} \varepsilon^{-Y}
$$

the viscosity is thus the product of the regular part $\eta_{\text {reg }}$ and a weak power law divergence $(Y \simeq+0.04)$. This result is in full agreement with the renormalization group theory of Siggia et al. [16].

In the light of the experimental and theoretical results discussed above, we have fitted our experimental data to several analytical forms assumed for the 
viscosity. For this purpose, the statistical refining method of Tournarie [17] has been used. This method is much more sophisticated than a least-squares fit.

Three main forms labelled (a), (b), (c) have been assumed for $\eta$ :
(a) $\eta=\eta_{\text {reg }} \varepsilon^{-Y}$
(b) $\eta=\eta_{\mathrm{reg}}+X_{2} \varepsilon^{-Y}$
(c) $\eta=\eta_{\mathrm{reg}}+X_{2}+X_{3} \log \varepsilon$.

In order to obtain a good accuracy for the singularity, the analytical form of $\eta_{\text {reg }}$ has to be determined carefully. For this purpose, we have tested six different analytical formulae (labelled a-1,.., a-6).

$$
\begin{aligned}
& \text { (a-1) } \eta_{\text {reg }}=\eta_{1} \exp \frac{E}{1+\varepsilon} \\
& \text { (a-2) } \eta_{\text {reg }}=\eta_{1}\left(1+X_{2}(\varepsilon)^{X_{5}}\right) \exp \frac{E}{1+\varepsilon} \\
& \text { (a-3) } \eta_{\text {reg }}=\eta_{1}\left(1+(\varepsilon)^{X_{2}}\right) \exp \frac{E}{1+\varepsilon} \\
& \text { (a-4) } \eta_{\text {reg }}=\eta_{1}\left(1+X_{2} \varepsilon\right) \exp \frac{E}{1+\varepsilon} \\
& \text { (a-5) } \eta_{\text {reg }}=\eta_{1}+X_{2} \varepsilon+X_{3} \varepsilon^{2} \\
& \text { (a-6) } \eta_{\text {reg }}=\eta_{1}+X_{2} \varepsilon+X_{3} \varepsilon^{2}+X_{4} \varepsilon^{3}
\end{aligned}
$$

(a-1) is the Arrhenius, a priori most probable form for $\eta_{\text {reg }} ;(a-2),(a-3),(a-4)$ are expansions around the Arrhenius law (a-1); (a-5) and (a-6) are expansions in powers of $\varepsilon$.

We only used in cases (b) and (c) the simplest Arrhenius law which is seen to give the best fit :

$$
\begin{aligned}
& \text { (b) } \eta=\eta_{1} \exp \frac{E}{1+\varepsilon}+X_{2} \varepsilon^{-Y} \\
& \text { (c) } \eta=\eta_{1} \exp \frac{E}{1+\varepsilon}+X_{2}+X_{3} \log \varepsilon .
\end{aligned}
$$

All the coefficients that appear on the right-hand side of equations $(8 \ldots 15)$ are temperature independent, except $\varepsilon=\frac{T-T_{\mathrm{c}}}{T_{\mathrm{c}}}$.

For an estimation of the quality of the fit, we have to take into account the standard deviation between calculated and measured values and the distribution of the errors, which is measured by a quality coefficient $Q$. This parameter equals 1 if the errors are randomly distributed, but drastically lowers if a systematical distortion occurs, as can be seen on figure 2 : in the case (c) where a systematical distribution of the relative errors appears, we get $Q=0.006$, whereas the value of $Q$ is 0.85 in the case (a-1).

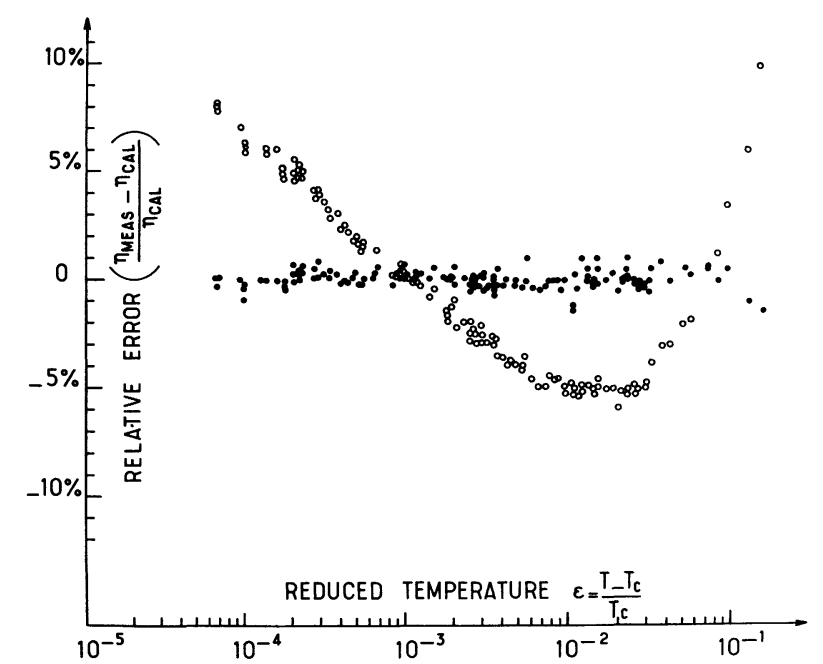

FIG. 2. - Plot of the relative errors against reduced temperature (Linear-Log scale). The circles refer to eq. (c) whereas the full dots refer to eq. (a-1).

The Arrhenius regular part (a-1) and its developments (a-2, a-3, a-4) give similar results for $E$ and $Y$ but the parameters $X_{2}$ and $X_{5}(\mathrm{a}-2, \mathrm{a}-3, \mathrm{a}-4)$ are not well defined. The analytical expansions (a-5, a-6) give nearly the same quality of the fit. But the most interesting result is that the best fit is given by the simplest Arrhenius law (a-1) with the least standard deviation and the greatest value of $Q$. Such a result has already been tested by Debye et al. [18] as a good empirical fit.

In the additive singular part, cases (b) $(Q=0.44)$ and (c) $(Q=0.006)$, the quality of the fit becomes very low : an additive law does not agree with our set of data, as shown on figure 2 , where the best fit (a-1) is compared to the worst fit (c).

4. Conclusion. - The shear viscosity of the critical mixture nitrobenzene- $n$-hexane has been measured in a large domain of temperature : from

$$
T-T_{\mathrm{c}}=0.003^{\circ} \mathrm{C} \text { up to } T-T_{\mathrm{c}}=45^{\circ} \mathrm{C} \text {. }
$$

At high temperature $\left(T-T_{\mathrm{c}}>10^{\circ} \mathrm{C}\right)$ the viscosity behaves according to a simple Arrhenius law. In the critical regime $\left(T-T_{\mathrm{c}}<10^{\circ} \mathrm{C}\right)$ the viscosity does not obey an additive law but can be written as a product of a regular part by a weak power law divergence : critical exponent $Y=0.043$. This result is in full agreement with a renormalization group treatment of the critical dynamics of binary fluids recently developed by Siggia et al. [16] i.e. $Y=0.04$ in three dimensions.

Acknowledgments. - The authors gratefully thank P. Calmettes for stimulating discussions. 


\section{References}

[1] See for instance Sengers, J. V., in Critical Phenomena, Proceedings of the International School of Physics Enrico Fermi ; M. S. Green Ed. (Acad. Press. N.Y.) 1972.

[2] Drapier, P., Bull. Acad. Sci. Belg. C 1 (1911) 621.

[3] Semenchenko, V. K. and Zorina, E. A., Dokl. Akad. Nauk SSSR 73 (1950) 331

[4] Szafronska, S., Bull. Acad. Sci. Cracovie A (1935) 110.

[5] Stein, A., Allegra, J. C. and Allen, F., J. Chem. Phys. 55 (1971) 4265

[6] See for instance ChEn, S. H. and Polonsky, N., Phys. Rev. Lett. 20 (1968) 909.

[7] Puglielli, V. and Ford, N., Phys. Rev. Lett. 25 (1970) 143.

[8] Piekara, A., Bull. Acad. Sci. Pol. (Ser. Sci. Chim. Geol.) A 305 (1933) 319.
[9] Carini, G., Maisano, G., Migliaro, P. and Wanderlingh, F., Phys. Rev. A 5 (1975) 1755.

[10] Oxтовy, D. W., J. Chem. Phys. 62 (1975) 1463.

[11] Beysens, D. and Zalcer, G., Phys. Rev. A 15 (1977) 765.

[12] Kawasaki, K. and Lo, S. M., Phys. Rev. Lett. 29 (1972) 48.

[13] Kawasaki, K., Ann. Phys. (N.Y.) 61 (1970) 1.

[14] Gulari, E., Collings, A. F., Schmidt, R. L. and Pings, C., J. Chem. Phys. 56 (1972) 6169.

[15] Calmettes, P., Submitted for publication to Phys. Rev. Lett. [16] Siggia, E. D., Halperin, B. I. and Hohenberg, P. C., Phys. Rev. B 13 (1976) 2110.

[17] Tournarie, M., J. Physique 30 (1969) 737.

[18] Debye, P., Chu, B. and Woerman, D., J. Polym. Sci. A 1 (1963) 249. 